\title{
TIPOLOGÍA DE TERRITORIOS TURÍSTICOS EN MÉXICO SEGÚN INCIDENCIA DE COVID-19
}

\author{
ÁlVARO SÁNCHEZ CRISPÍN \\ asc@igg.unam.mx \\ ENRIQUE PROPIN FREJOMIL \\ propinfrejomil@igg.unam.mx \\ JosÉ MARÍA CASADO IZQUIERDO \\ chema@igg.unam.mx \\ Instituto de Geografía \\ Universidad Nacional Autónoma de México
}

Este trabajo propone una tipología de territorios turísticos con relación a la incidencia de COVID-19, la disponibilidad de infraestructura física para enfrentar la pandemia y la disminución del empleo en el sector turístico en México, a escala municipal, en el período marzo-junio de 2020. Los hallazgos principales de la investigación, revelados mediante coordenadas cartesianas y representados en forma cartográfica, muestran 16 combinaciones tipológicas territoriales que comprenden desde las que se asocian con condiciones de mayor incidencia, hasta las que gozan de una situación sanitaria comparativamente mejor.

Palabras clave: México, geografía de la salud, COVID-19, territorios turísticos, tipología

\section{A TYPOLOGY OF TOURIST DESTINATIONS IN MEXICO ACCORDING TO THE OCCURRENCE OF COVID-19}

This work proposes a typology of tourist destinations in Mexico, based on the occurrence of COVID-19 at a municipal level, in the period comprising from March to June 2020. To achieve this, statistics on the number of cases, number of deaths, availability of health facilities and loss of jobs in the tourist sector were weighed up. The main results of the research, revealed through cartesian coordinates and represented in cartographic form, determined sixteen types of territorial combinations, comprising from those associated with conditions of higher incidence to the relatively safe sanitary circumstances of certain places.

Keywords: Mexico, geography of health, COVID-19, tourist territories, typology 


\section{Introducción}

s reconocido en la generalidad que, a fines de 2019, el COVID-19', tuvo su punto primario de difusión en la ciudad china de Wuhan, que se asienta en la porción media del río Chang Jiang o Yang-tsé, cuya cuenca está densamente poblada; aguas abajo, se encuentran ciudades relevantes para la economía mundial como Nanjing y Shanghai.

Esta parte del centro de China dispone de alta conectividad y accesibilidad con el resto del mundo. Los sectores secundario y terciario de su economía forman parte de cadenas productivas globalizadas cuyos vínculos se extienden particularmente a Europa occidental y la costa oeste de Estados Unidos. Tal circunstancia favoreció la dispersión geográfica del virus, por diferentes medios de transporte, en olas sucesivas y con efectos demoledores territoriales diferenciados; con particular afectación, semanas después, en lugares como el norte de Italia.

Para fines de junio de 2020, la pandemia había contagiado a diez millones de personas y causado la muerte a 500 mil (Johns Hopkins University, 2020), a la par de las graves consecuencias negativas sobre la economía mundial.

En México se tiene registro del primer caso de COVID-19 el 28 de febrero de 2020. Es muy probable que los vectores iniciales de transmisión se relacionen con la llegada de personas procedentes de lugares ya afectados por la pandemia, ubicados en Asia oriental, Europa occidental (España, Francia e Italia) o Estados Unidos, articulados y comunicados eficientemente con diferentes puntos de entrada al país, en especial sitios turísticos como Tijuana, Los Cabos, Cancún y la capital nacional (El Universal, 2020). Cuatro meses después, el país contaba con 196 mil casos y un registro superior a los 24 mil muertos. Estas cifras, al ser comparadas entre sí, arrojan un cociente más alto que su correspondiente a nivel mundial (Conacyt, 2020).

En cuanto se percibió la magnitud del contagio, se suscitó en muchos países un interés académico y gubernamental por fomentar el inicio y desarrollo de investigaciones sobre esta enfermedad, desde diferentes perspectivas, entre ellas la de las ciencias biológicas y de la salud, de las matemáticas y las ciencias sociales. En el caso de los estudios geográficos, uno de los primeros esfuerzos colectivos por examinar esta nueva circunstancia de salud pública mundial se generó en Argentina, en la Universidad de

Enfermedad provocada por el virus SARS-CoV-2, emparentado con aquellos que provocan el síndrome respiratorio agudo grave o SARS y el síndrome respiratorio de Medio Oriente (MERS). 
Luján, a cargo del doctor Gustavo Buzai, cuyo equipo de trabajo tiene experiencia reconocida en el campo de la geografía cuantitativa, los sistemas de información geográfica y la geografía de la salud. Este cuerpo académico publicó un dossier en el que se explican distintas expresiones territoriales generadas por la difusión del COVID-19, a nivel mundial y regional latinoamericano, incluido México (Buzai, 2020).

La presente investigación se acoge, por un lado, a la experiencia del grupo de trabajo de geografía del turismo del Instituto de Geografía de la Universidad Nacional Autónoma de México, para seleccionar los destinos turísticos del país que fueron considerados en el estudio. Por otro lado, se adhiere a la tradición de análisis anclado en la geografía de la salud, especialidad en la que concurren distintas maneras de examinar el territorio en cuanto a aparición, desarrollo, difusión y prevalencia de una enfermedad, y a la existencia de infraestructura y personal profesional calificado para atender las consecuencias de un padecimiento.

Así contextualizado, la finalidad de este trabajo es mostrar cómo la pandemia generó un patrón territorial diferenciado, creado por su difusión al interior de México, en cuanto al número de contagios y decesos, la existencia de infraestructura para enfrentar la expansión del virus, con especial referencia a destinos turísticos de relevancia, y cómo en estos se generó una consecuencia económica negativa, reflejada en la disminución de empleos formales de dicho sector. Los resultados del trabajo quedan concretados en una tipología de territorios turísticos seleccionados que evidencia las diferencias de la incidencia de COVID-19.

Esta reflexión se realiza a partir de dos momentos: a) al inicio de la aparición de la enfermedad y b) Al término de la Jornada de sana distancia promovida por el gobierno federal, a través de su Secretaría de Salud, a inicios de marzo e inicios de junio de 2020, respectivamente. Este esfuerzo académico puede ser de utilidad en la generación de propuestas de acción territorial que, basadas en el desarrollo del pensamiento espacial, coadyuven a enfrentar y remediar la pandemia, en especial en lo que concierne a lugares con actividad turística notoria.

\section{Antecedentes investigativos}

En la actualidad, la parte de la geografía que examina el binomio salud-enfermedad, en cualquier escala de análisis y con una acotación temporal, se llama geografía de la salud. Se le designa con tal nombre a partir de una decisión tomada en 
el Congreso de geografía de Moscú, en 1976, organizado por la Unión Geográfica Internacional. En ese contexto, queda establecido que la hasta entonces llamada geografía médica se transforma en geografía de la salud, a la que compete el estudio de dos grandes temas: la geografía de las enfermedades (geografía médica) y geografía de los servicios de salud (Villerías et al., 2020).

A través de su abordaje metodológico, es posible develar la secuencia de difusión de enfermedades, en especial las epidémicas, determinar y cartografiar los patrones de distribución geográfica de personas afectadas por padecimientos específicos, a distintas escalas de representación, y mostrar la disponibilidad de infraestructura básica y especializada para atender problemas de salud pública (clínicas, hospitales), así como de personal capacitado para atenderlos (médicos, enfermeros, técnicos).

En el estudio de los procesos asociados con la expansión territorial de enfermedades epidémicas hay que recurrir, precisamente, a la representación cartográfica, a fin de reconocer el comportamiento de la incidencia y prevenir el contagio o tomar acciones para contrarrestar efectos negativos generados por un padecimiento. Es importante acotar que el mapa no es una mera representación de la realidad espacial sino una forma de pensar la relación entre las comunidades bacteriano-virulentas, los huéspedes humanos y el ambiente en el que las enfermedades florecen (Koch, 2017). Esta manera de simbolizar los procesos epidémicos y pandémicos facilita pensar en acciones claras de remediación, diferenciadas territorialmente, ante una situación de emergencia sanitaria.

Con relación al tema de COVID-19 y su explicación desde la perspectiva de la geografía, en el contexto de las publicaciones académicas en castellano, se pueden indicar dos referencias obligadas:

La primera, ya señalada, es el dossier Análisis geográfico de COVID-19, publicado por la revista Posición de la Universidad de Luján, Argentina (Buzai, 2020). Allí se encuentran trabajos que examinan características del proceso de difusión del contagio en cuanto a las tendencias espacio-temporales en México y otros países (García de León, 2020); de igual forma, se hace una valoración de la vulnerabilidad ante la llegada de COVID-19 a México, por entidad federativa, por medio de la ponderación de distintas variables (G. Santana, 2020); se demuestra asimismo, en otra investigación, que el patrón geográfico de difusión del contagio no fue uniforme y tuvo núcleos primarios de expansión en grandes ciudades, en destinos turísticos de jerarquía superior y en la frontera norte (M. Santana, 2020). 
La segunda referencia académica, antecedente al presente estudio, es un atlas digital realizado por el Instituto de Geografía (2020) en el que se muestra la vulnerabilidad urbana ante COVID-19, en zonas metropolitanas de México. A partir de la cartografía contenida en el atlas, se pueden inferir aspectos de relevancia para explicar la vulnerabilidad de la población que vive en sitios turísticos como Tijuana (Padilla et al., 2020), Acapulco (Granados et al., 2020), Cancún (Gasca, 2020) y Mérida (Salmerón y Hernández, 2020), en el escenario de la pandemia; sin embargo, el atlas no contiene casos de otros destinos que no han conformado una zona metropolitana o cuyo tamaño demográfico es pequeño. Este atlas tuvo como referencia metodológica un trabajo previo sobre un índice de vulnerabilidad ante COVID-19 para México, con base en información municipal (Suárez Lastra et al., 2020).

\section{Incidencia de COVID-19 en el territorio mexicano}

Antes de examinar la presencia de COVID-19 en los territorios turísticos incluidos en este trabajo, es necesario contextualizar el caso de México en la región de América Latina y el Caribe, reconocida por la Organización Mundial de la Salud (OMS). Un indicador fundamental es la cantidad de muertes provocadas por su difusión; las cifras oficiales se publican por cada 100 mil personas. Al 25 de junio de 2020, fecha referente a un momento de ascenso de la pandemia en la región, las cifras más altas se registraban en: Saint Martin (37 decesos por 100 mil personas), Perú (27), Brasil y Chile (26, en cada caso) y Ecuador (25); México venía inmediatamente después con una tasa de 19 por 100 mil personas (The New York Times, 2020).

Excepto en el caso de Montserrat y Panamá, con valores de 17 y 13, respectivamente, todos los demás países y territorios de la región tenían tasas inferiores a diez muertes por cada 100 mil personas; en varias islas del arco del Caribe oriental (San Vicente y las Granadinas, Granada, Santa Lucía, Dominica, San Kitts y Nevis, y Anguilla) no se registraban muertes asociadas con COVID-19. Las tasas de mortalidad de los países vecinos al sur de México eran muy bajas: Belice (0.5) y Guatemala (3), cifras que contrastan con las del país vecino del norte, Estados Unidos, 37 decesos por 100 mil personas, una de las más altas del mundo y lugar de origen de la mayoría de los turistas que visita el territorio nacional.

De lo anterior se desprende que México ha sido uno de los países más afectados en la región, en cuanto a número de personas fallecidas a causa del contagio de 
COVID-19. Esta situación seguramente será valorada en los meses próximos, al momento de que turistas extranjeros, una vez abiertas las fronteras nacionales, decidan a qué destinos viajar, y cuyo razonamiento y decisión incluirá la ponderación sobre la cantidad de contagios y decesos provocados por COVID-19, durante este año. ${ }^{2}$

Como se indicó, para el mismo 25 de junio de 2020, las cifras oficiales en México respecto a la distribución geográfica por estados de los casos de contagio y decesos asociados con COVID-19, eran de más de 196 mil personas afectadas y poco más de 24 mil muertes. En términos absolutos, se presentaba una aglomeración de contagios en el centro del país (Ciudad de México, México, Morelos, Puebla, Tlaxcala e Hidalgo) cuyo conjunto representaba casi la mitad del total nacional. En la región del Golfo de California (Baja California, Baja California Sur, Sonora, Sinaloa y Nayarit), los casos superaban la cifra de 25 mil o el 13\% del país; en la costa del Golfo de México (Tabasco y Veracruz) había un importante número de personas afectadas (18 mil), lo mismo que en la península de Yucatán (Campeche, Yucatán y Quintana Roo) con poco más de 8 mil casos.

Estas cuatro áreas del territorio nacional concentraban el 75\% de los casos registrados hasta esa fecha. Varios destinos turísticos importantes están emplazados ahí y han sido afectados desde el inicio de la pandemia. Las entidades con menos casos eran Durango, Nayarit, Zacatecas y Colima donde ni el número de contagios, ni la cantidad de decesos era notable.

De manera similar, el patrón de distribución geográfica del número total de muertes producidas por COVID-19 tenía un núcleo de concentración alrededor de la capital nacional, donde los estados indicados en el párrafo anterior, en su conjunto, contenían la mitad de los decesos en el país. Dos entidades del Golfo de California (Baja California y Sinaloa), y dos del Golfo de México (Tabasco y Veracruz), declaraban cifras arriba de mil decesos cada una. En estas entidades se concentraba casi el $75 \%$ del total de personas fallecidas a causa de la pandemia. Tal patrón geográfico de concentración también se revela si se consideran las tasas de contagio y decesos, por cada 100 mil habitantes. Las entidades con tasas de contagio y mortalidad más

\footnotetext{
2 El 1 de julio, la Unión Europea abrió sus fronteras a un selecto número de países entre los que no se encuentra México, lo que en la práctica limita los vuelos entre ambos territorios. Así, aunque ciertas aerolíneas han reanudado sus vuelos a México o incrementado su frecuencia, algunas han mantenido la cancelación de sus vuelos en los próximos meses (British Airways y las españolas Wamosair y AirEuropa). Asimismo, y desde el 20 de marzo, se mantiene la suspensión de viajes no esenciales (y por tanto del turismo) entre México, Estados Unidos y Canadá.
} 
altas eran la Ciudad de México, México, Tlaxcala, en el centro del país; Baja California, Sonora y Sinaloa en la región del Golfo de California; Tabasco y Quintana Roo.

Los primeros registros oficiales de personas afectadas por COVID-19 corresponden a casos en el Valle de México (cuatro en total, el 28 de febrero de 2020), y uno por ciudad en Monterrey, Aguascalientes, Tijuana y Pachuca; de este conjunto, el Valle de México, Monterrey y Tijuana son destinos turísticos preferenciales, con alta conectividad y accesibilidad terrestre y aérea (Propin y Sánchez, 2007; Propin et al., 2017). Estos son tres núcleos primarios desde que inició la pandemia y donde la llegada de casos importados habría tenido un papel esencial en su llegada y difusión en el país (El Universal, 2020).

Para el inicio de la fase 2, o de confinamiento voluntario de las personas en sus hogares, fechada el 24 de marzo de 2020, hay un incremento considerable en el número de contagios, con una cifra abultada que corresponde al Valle de México (440). Se añaden a este grupo, además de Monterrey y Tijuana, las ciudades de Guadalajara, Puebla, Mérida, Cancún, San Luis Potosí, Mexicali y León. Se trata de grandes núcleos urbanos del país, algunos de los cuales presentan un sector turístico de relevancia como Guadalajara y Puebla, y de destinos turísticos preferenciales como Mérida y Cancún, cuyas cifras de personas contagiadas, en comparación con su tamaño demográfico, son altas.

Más adelante, al inicio de la Jornada de sana distancia, el 21 de abril de 2020, que se prolongaría por más de seis semanas, la constitución del grupo de municipios con mayor número de personas confirmadas con COVID-19 registra un cambio. Siguen en la lista los tres núcleos urbanos originales: el Valle de México (casi 7 mil personas infectadas), Tijuana (segundo lugar nacional con 826 casos) y Monterrey (263). Es notoria la aparición de destinos turísticos como Ciudad Juárez y Los Cabos, y la permanencia de Cancún (457 casos) y Mérida (254). Este incremento en las cifras, con respecto a los destinos turísticos, es indicativo de que la llegada, en grandes cantidades y por motivos de ocio y recreación, de personas provenientes del exterior (entendida esta palabra como fuera del municipio) contribuyó a generar tal circunstancia.

El 17 de mayo de 2020, como una de las primeras acciones del gobierno federal para regresar a la vida cotidiana en el contexto de la pandemia, se publicó un listado de los municipios denominados de La Esperanza; se trató de 324 demarcaciones municipales esparcidas en 14 entidades federativas, ninguna de las cuales tiene 
una población mayor a 30 mil personas, muchas de ellas alejadas y poco accesibles, sin registro de contagios por COVID-19, ni vecinas a municipios que sí los tenían.

En el contexto que interesa a esta investigación, la revisión de tal listado indicó que algunos lugares, ubicados en Guerrero, Jalisco, Oaxaca y San Luis Potosí, mostraban un cierto grado de actividad turística; entre ellos se pueden mencionar los de la costa chica de Guerrero y su continuación en la costa oaxaqueña, Talpa en Jalisco (sitio de montaña) y Catorce en San Luis Potosí (centro minero del altiplano con patrimonio cultural destacado). Ninguno de los destinos turísticos con cierto nivel de importancia en México fue incluido en el catálogo de municipios de La Esperanza, lo que de alguna manera revela que la llegada de personas, extranjeras y nacionales, a esos destinos produjo en mayor o menor medida contagios asociados con COVID-19.

El primero de junio de 2020 concluyó la Jornada de sana distancia, tres meses después de la aparición de los primeros casos de personas afectadas con COVID-19. Los tres grandes núcleos urbanos, que desde un inicio de la pandemia estuvieron en la lista de los diez primeros territorios con contagios, permanecieron en ella: el Valle de México, Tijuana y Monterrey. La mayor cantidad de personas registradas como confirmadas se encuentra en el Valle de México, con más de 42 mil casos. Cada una de las otras nueve aglomeraciones urbanas que integran este grupo tiene más de mil 400 registros de personas confirmadas con COVID-19. Al Valle de México, Tijuana y Monterrey, se suman dos destinos turísticos de relevancia para la economía turística nacional: Guadalajara y Cancún.

La explicación de una gran cantidad de casos en las tres ciudades más pobladas del país (Valle de México, Guadalajara, Monterrey) se relaciona con su peso demográfico. Sin embargo, en el caso de Cancún la explicación se debe a la llegada de un número considerable de turistas producido justo antes del inicio de la pandemia, que coincidió con uno de los picos de máxima afluencia de turistas internacionales a ese destino de playa.

\section{Fuentes de información y métodos}

Para llevar a cabo este trabajo, se consultaron diversas fuentes de información, en particular las que dependen del gobierno federal, como la Secretaría de Salud, cuya Dirección General de Epidemiología hace del conocimiento público, diariamente, 
cifras en cuanto al número de contagios de COVID-19, casos activos y personas faIlecidas (DGE-SSA, 2020). Con el propósito de ampliar el marco interpretativo de la tipología, se recurrió a otras fuentes oficiales para obtener datos respecto a la existencia de unidades médicas, a nivel nacional y por municipio; al mismo tiempo, se compiló información del Instituto Mexicano del Seguro Social (IMSS) relacionada con el número de asegurados en el sector turismo en el período del 29 de febrero a 30 de abril de 2020; de igual manera, del Consejo Nacional de Población (Conapo) se obtuvieron cifras de población municipal, proyectadas al año 2018 y 2020 (SSA, 2020; IMSS, 2020; Conapo, 2018b).

Los datos compilados fueron trabajados a través de la siguiente metodología:

\subsection{Selección de los territorios turísticos}

Para la conformación del conjunto de lugares integrados a la investigación, se seleccionaron 53 territorios turísticos a los que se les reconoce con su nombre oficial en la figura 1, excepto en aquellos casos cuya denominación no facilita su identificación: Benito Juárez, Quintana Roo, referido líneas abajo como Cancún; Centro, municipio donde se encuentra la capital tabasqueña, Villahermosa; Othón P. Blanco que contiene a Chetumal; Solidaridad, referido más adelante como Playa del Carmen; Bahía de Banderas, municipio de Nayarit donde se ubica Nuevo Vallarta; y Zihuatanejo de Azueta, que comprende el destino turístico de Ixtapa (figura 1). El razonamiento que fundamentó la elección de los territorios se enlista a continuación:

1. En el grupo seleccionado debería haber, por lo menos, un territorio de cada entidad federativa, aunque no se tratara de un destino turístico de relevancia (Propin y Sánchez, 2007; Propin et al., 2017), esto con el fin de contar con lugares susceptibles de comparación distribuidos por todo el país. Los casos de los estados de Durango y Tabasco ejemplifican esta situación, pues sus capitales estatales fueron incluidas en el listado sin ser destinos de alta jerarquía en el turismo en México.

2. Todos los territorios incluidos tienen una población igual o mayor que $100 \mathrm{mil}$ habitantes. Se consideró este como un límite inferior pertinente a la ubicación de infraestructura hospitalaria. Asimismo, un núcleo con este tamaño demográfico está relacionado con niveles aceptables de conectividad y accesibilidad con el resto del país y es de relevancia para la actividad turística. 
3. Algunos sitios fronterizos fueron considerados en la lista para tener un panorama de lo que acontece en sitios contiguos a países vecinos. Varios de ellos son destinos importantes para el turismo internacional como Tijuana, pero otros fueron incluidos en el grupo por el hecho de incorporar los cruces terrestres o fluviales entre México y Estados Unidos (Piedras Negras), México y Guatemala (Tapachula), y México y Belice (Chetumal). No se consideraron lugares de la frontera norte cuya actividad turística ha sido recientemente afectada por la inseguridad, en particular los ubicados en Tamaulipas.

4. Las grandes aglomeraciones urbanas del país también forman parte de este grupo de territorios. La mancha urbana del Valle de México (con 75 municipios, incluidas las 16 alcaldías de la Ciudad de México), las áreas metropolitanas de Guadalajara, Monterrey y otras ocho ciudades que en 2020 tenían más de un millón de personas, fueron agregadas a la lista. Varias de estas aglomeraciones urbanas son destinos turísticos preferenciales, en particular la capital del país. El resto de los territorios que aparece en la figura 1 se eligió de dos listados de destinos turísticos de México: uno sobre tipología de destinos turísticos preferenciales (Propin y Sánchez, 2007) y otro sobre niveles de selectividad territorial (Propin et al., 2017).

\subsection{Identificación de los indicadores temáticos}

La información disponible marcó indicadores diversos que permitieran demostrar las diferentes circunstancias existentes, relacionadas con el COVID-19 en los territorios turísticos. En este proceso de discriminación informativa, primó el criterio de minimizar la cantidad de indicadores con el propósito de disminuir el nivel de abstracción interpretativa y, consecuentemente, visibilizar, en forma gráfica, el comportamiento cuantitativo relacionado de dichos elementos; en este orden de ideas, se seleccionaron los cuatro indicadores temáticos siguientes:

a) Tasa de contagio. Contagiados por cada 10 mil habitantes al 1 de junio de 2020 . Esta medición relativiza la información difundida de cantidad de contagios; es de esperar que, a mayores concentraciones de población en condiciones de acentuada movilidad cotidiana, le corresponda, por probabilidad, mayor cantidad de contagiados; sin embargo, el mismo escenario informativo, presentado en términos relativos, permite aprehender la realidad desde otra dimensión indicativa: la concentración poblacional de los contagiados. 
Figura 1. Territorios turísticos seleccionados

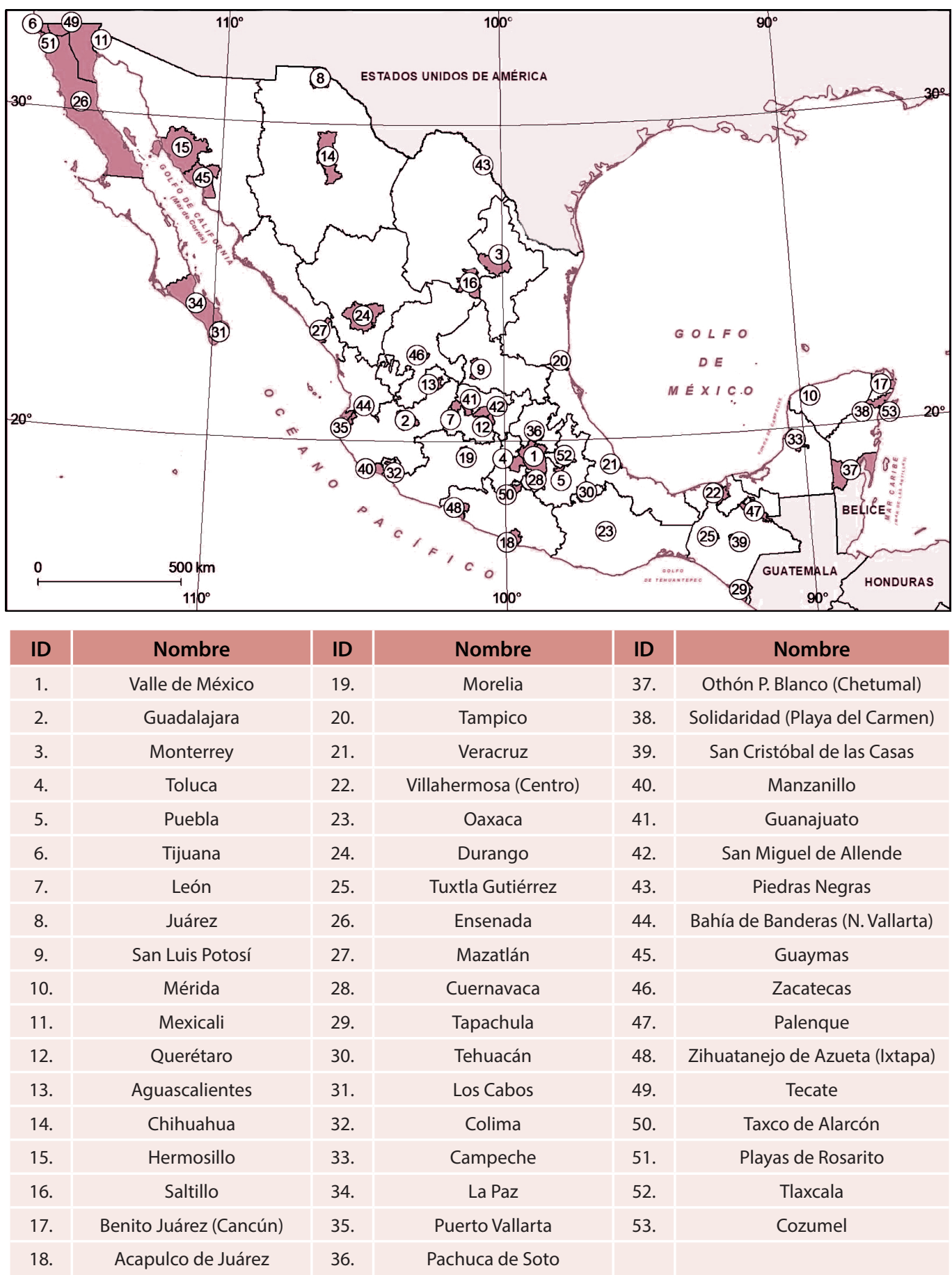

Nota: ID asignado según proyección de población total para el año 2020 (Conapo, 2018a, 2018b).

Fuente: Elaboración propia con base en Propin y Sánchez (2007), Propin et al. (2017); 
b) Tasa de letalidad. Porcentaje de fallecidos sobre contagiados hasta el final de la Jornada de sana distancia, 1 de junio de 2020. Esta medición, sensiblemente relevante, representa un asunto controversial cuando se analizan las estadísticas del gobierno sobre la pandemia en el país, al presentar cifras muy superiores a las de otras naciones, donde tienden a alcanzar valores del $4 \%$ frente al casi $12 \%$ en México; en siete espacios turísticos destacados se supera el 20\%: Taxco, Tijuana, Cozumel, Ciudad Juárez, Playas de Rosarito, Cancún y Cuernavaca.

Estos dos primeros indicadores son vertebrales en este trabajo debido a su ligamento temático directo con el fenómeno que se examina; por ello, son los adoptados para la diferenciación de los tipos de territorios turísticos según la incidencia de COVID-19. Hay que precisar que la utilización de los datos oficiales del país (con independencia de su certeza) se hace para generar un testimonio académico de un hecho histórico y demostrar un razonamiento esencial de la geografía: ante la impronta de un mismo suceso (adverso o propicio), los lugares responden de disímil manera de acuerdo con sus singularidades locales.

c) Disponibilidad de camas hospitalarias. Camas por cada 10 mil habitantes. La valoración de la capacidad de atención hospitalaria alentó la elección de este indicador; en particular, lejos de lo esperado, exhibió contrastes acentuados entre los territorios turísticos lo que, sin duda, es un asunto que requiere la atención de las autoridades competentes, no solo en las circunstancias actuales de emergencia sanitaria, sino en el acontecer ordinario de los territorios turísticos que se caracterizan por la importante presencia de una población flotante no residente y, por lo tanto, no considerada en el denominador de este indicador.

d) Dinámica temporal de trabajadores asegurados en el IMSS correspondientes al sector turístico, evolución expresada en términos porcentuales de acuerdo con la siguiente fórmula:

[(Asegurados al 30/04/20 - Asegurados al 29/02/20) / Asegurados al 29/02/20]*100

Se eligió esta dimensión relativa para la comparación entre territorios, que evade, como en el caso del primer indicador, el dato cuantitativo absoluto, aunque un mismo porcentaje puede representar cifras absolutas muy dispares. En Cancún la caída es del $22.9 \%$ pero supone 21.9 mil trabajadores menos (trabajadores que perdieron su empleo); en Acapulco la caída es muy similar (22.7\%), pero solo representa la pérdida de 4.5 mil empleos. 
Otro aspecto por considerar es la limitación informativa; el indicador refiere solo la evolución del empleo relacionada con los trabajadores del turismo asegurados en el IMSS, lo que podría ser considerado como empleo formal, por lo cual la pérdida total de empleos en el sector turístico sería seguramente mucho mayor si se considerara, por un lado, el empleo informal y el autoempleo y, por el otro, el empleo indirecto. Por ejemplo, servicios de lavandería para los hoteles y cualquier otro tipo de servicio y proveeduría "externa" al sector turismo. No obstante, esta medición sirvió para introducir someramente una de las tantas consecuencias asociadas con la contingencia sanitaria.

\subsection{Procesamiento metodológico de los indicadores}

La exploración inicial realizada para elaborar la tipología se hizo sobre un plano cartesiano, por su dúctil manejo descriptivo-interpretativo (Acevedo et al., 2010). Para su empleo en este trabajo, se precisaron dos restricciones técnicas que enfatizaran las diferencias y similitudes territoriales:

a) Dar mayor peso temático, en la categoría de tipo (orden jerárquico superior), a la relación entre los dos primeros indicadores (contagio y letalidad) y adoptar las concordancias entre los dos restantes como referentes de los subtipos: el tercer indicador (disponibilidad de camas) exhibe información contextual y el cuarto (asegurados IMSS/empleo en sector turismo) informa sobre consecuencias. Estos dos indicadores finales, sobre los que se conforman los subtipos, permiten considerar escenarios diversos que señalan condiciones favorables o no de los tipos fundamentados según la incidencia directa de COVID-19.

b) Así, se revelaron cuatro subtipos (los cuatro existen en cada uno de los cuatro tipos); esto hace que la tipología diferencie 16 combinaciones de atributos, de manera que los cuatro tipos de territorios, según mayor o menor incidencia del virus, se diferencian, a su vez, por las mejores o peores condiciones de los territorios. Las 16 combinaciones tipológicas oscilan entre las que señalan condiciones desfavorables en el tipo de mayor incidencia (mayores tasas de contagio y letalidad) y los que indican condiciones favorables en tipos de menor incidencia del virus (menores tasas).

c) Resignificar el comportamiento cuantitativo de los indicadores, mediante la adopción de los valores medios nacionales en la intersección de los ejes de coordenadas cartesianas. En consecuencia, se identifican cuatro tipos (según cua- 
drantes) con comportamientos bidimensionales de los indicadores comparados con sus respectivos valores medios nacionales (figura 2): los dos cuadrantes superiores comparten en común los altos valores relativos de " $y$ ", mientras que " $x$ " fluctúa en forma desigual entre los mayores valores a la derecha y los menores a la izquierda: esto facilita la comparación entre los campos cartesianos; por ejemplo, entre los dos inferiores y entre los diagonales opuestos (el superior derecho representa el escenario opuesto del inferior izquierdo).

Figura 2. Diferenciación esquemática según comportamiento cuantitativo de los indicadores por cuadrante

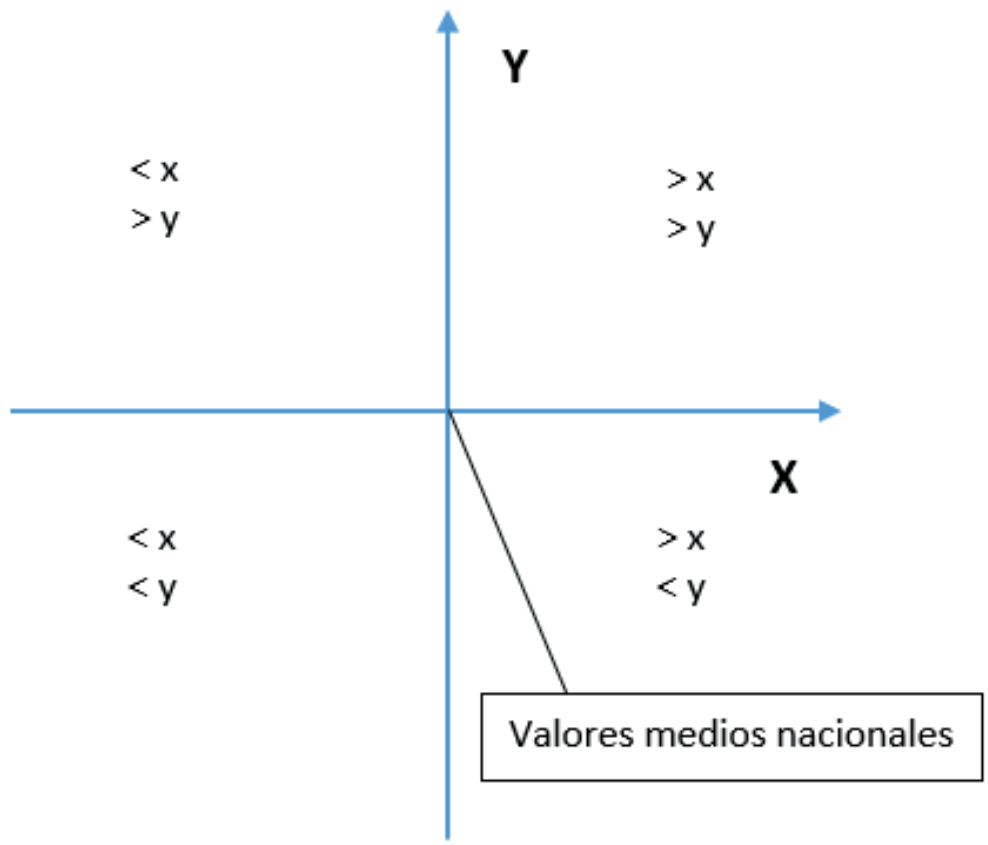

Fuente: Elaboración propia con base en Acevedo et al. (2010).

Cabe apuntar que toda tipología reúne las dos expresiones extremas en el entendimiento de los territorios: la noción de singularidad (esencial en los estudios de caso y paso inicial de cualquier tipificación) representa la relación cuantitativa de los datos iniciales referidos a cada territorio; esta noción, para efectos de la tipología, cede paso a la dimensión opuesta, la generalidad de los territorios (adoptada en este trabajo), que se logra a través de la aplicación de procedimientos metodológicos de clasificación y comparación (Thürmer, 1983; Propin, 2003; Propin et al., 2017). 


\section{Hallazgos de investigación}

La clasificación tipológica de los territorios turísticos, según incidencia de COVID-19, está modelada por las características geográficas del país, como la heterogeneidad de condiciones naturales concernientes al tamaño del territorio nacional, la localización geográfica de los lugares (costeros, fronterizos e interiores), la concentración y consecuente movilidad de la población; así como por otros particulares: la accesibilidad (terrestre, aérea y marítima) y la concentración de la infraestructura turística y hospitalaria.

\subsection{Diferenciación de los tipos y subtipos de territorios turísticos}

El cruce de los dos primeros indicadores diferenció los cuatro tipos de territorios turísticos según la incidencia de COVID-19 (figura 3). Las denominaciones y ordenamiento de los tipos (con números romanos) y de los subtipos (con letras) fue intencional: su orden indica el tránsito del peor escenario ( $\mathrm{l}$ o $A)$ al mejor en términos relativos (IV o D); este protocolo indica el grado de severidad de la incidencia de la pandemia en los territorios. Por otro lado, en la descripción de los tipos y subtipos, se utilizan expresiones valorativas (mayor-alta o sus opuestos) que tienen como referencia los valores medios nacionales de cada indicador.

Se evidencia una desigual distribución de los territorios turísticos entre cuadrantes (que asignan los tipos), con respecto a los valores medios nacionales de las tasas de contagio (8.2\%) y de letalidad (11.8\%): el IV, que acoge las menores tasas de ambos indicadores, es el más numeroso (45\% del total de los 53 territorios seleccionados), mientras que el escenario crítico opuesto (cuadrante I) reúne solo el $17 \%$. 
Figura 3. México: Tipos de territorios turísticos - Relación entre las tasas de contagios y de letalidad

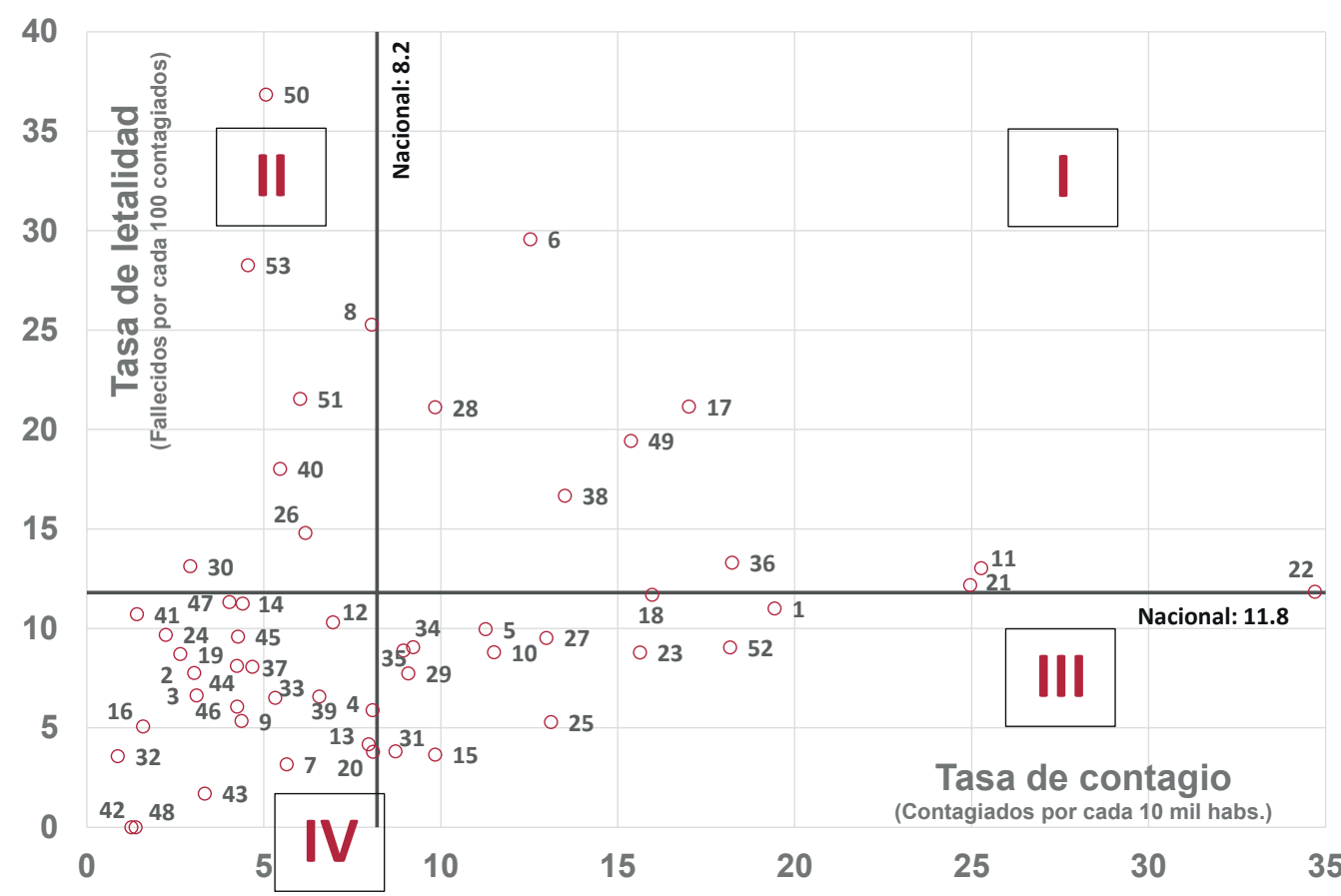

Nota: Ver ID de los territorios turísticos en figura 1.

Fuente: Elaboración propia con base en Conapo (2018b); DGE-SSA (2020).

Los tipos I y II (los más críticos por la incidencia del virus) tienen dos particularidades: poseen menor cantidad de casos (I-17\%; II- 13\%) y una mayor dispersión de valores, entre los que se destacan los casos extremos de Villahermosa, con la tasa más alta de contagio del grupo de territorios estudiados, pero con una menor tasa de letalidad, y Taxco con la mayor letalidad, pero con menor contagio; estudios de caso podrían brindar explicaciones sobre las condiciones específicas que mediaron en esos escenarios.

En sentido opuesto, se detectan territorios turísticos con tasas de contagio y letalidad bajas (tipo IV), un comportamiento que se da en San Miguel de Allende e Ixtapa-Zihuatanejo (ambos con letalidad nula); el mismo escenario (baja tasa de letalidad) acontece en Los Cabos (tipo III) a pesar de que tiene una tasa de contagio relativamente mayor (8.7 por cada 10 mil habitantes) que la de los dos casos anteriormente mencionados. 
Por su parte, los subtipos, derivados de la relación entre disponibilidad de camas hospitalarias y variación temporal de los empleos formales en el sector turístico muestran un comportamiento estadístico semejante al de los tipos. Cabe señalar que el ordenamiento de los cuadrantes se alteró para mantener la misma lógica empleada en los tipos: el primer cuadrante $(A)$ reúne las peores condiciones y el último (D) las mejores; así, las condiciones críticas aquí se muestran no en el cuadrante superior derecho (como en el caso anterior), sino en el inferior izquierdo (el opuesto) que reúne los territorios turísticos con menor disponibilidad de camas hospitalarias y mayores caídas en el empleo turístico formal (figura 4).

El subtipo $D$, con mejores condiciones en los dos indicadores, concentra el $58 \%$ de los territorios examinados, mientras que a los tipos críticos (A y B) corresponden el $15 \%$ y $13 \%$, respectivamente. Aunque el panorama del conjunto puede ser considerado como favorable, no es desacertado señalar que existen territorios con disponibilidad de camas hospitalarias por debajo de la media nacional (condiciones desfavorables para atender las emergencias sanitarias) y con mayor afectación en los empleos turísticos (según la potencialidad informativa del indicador).

Ejemplo de ello son Bahía de Banderas, el de mayor descenso en el porcentaje de afiliados al IMSS en el sector turístico, y San Miguel de Allende, con la menor disponibilidad de camas hospitalarias del conjunto. Otro lugar afectado en extremo, por la caída del empleo formal en el sector turismo, es Ixtapa-Zihuatanejo (tipo B). En el sentido opuesto, el tipo D se halló en Tlaxcala, con la mayor disponibilidad de camas hospitalarias, y Colima, con la evolución más positiva en el empleo formal dentro del sector turismo. 
Figura 4. Subtipos de territorios turísticos - Relación entre disponibilidad de camas hospitalarias y variación de asegurados en sector turismo

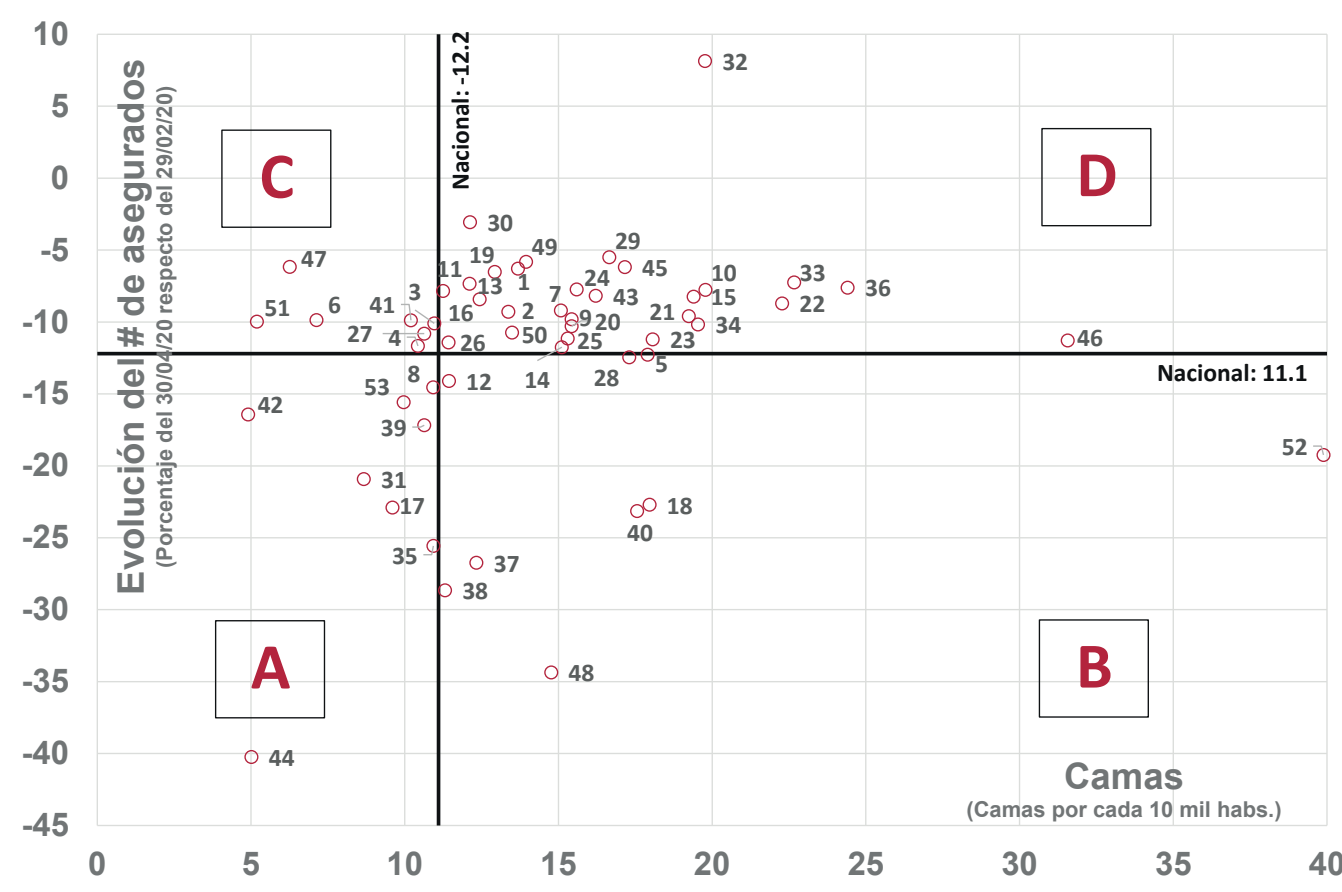

Nota: Ver ID de los territorios turísticos en figura 1.

Fuente: Elaboración propia con base en Conapo (2018b); SSA (2020); IMSS (2020).

\subsection{Expresión tipológico-espacial de los territorios turísticos}

La revelación de la tipología de territorios turísticos según incidencia de COVID-19 condujo a su reconocimiento espacial debido a una interrogante general: ¿la localización y vecindades geográficas entre los territorios turísticos puede llegar a explicar causalmente la incidencia de COVID-19 en los mismos? La figura 5 facilita hacer algunas observaciones relacionadas con esta pregunta. Con el propósito de ilustrar la relevancia de los territorios turísticos en el contexto nacional, para la elaboración del mapa se empleó la variable de la cantidad de turistas en 2018 (Datatur, 2018); no obstante la fecha, aunque es una imagen cuantitativa irreal para las condiciones actuales, permitió asociar las características distintivas de los tipos revelados con la jerarquía regular de territorios turísticos en México, según el criterio de afluencia total de turistas. 
Figura 5. Tipología de territorios turísticos según incidencia de COVID-19

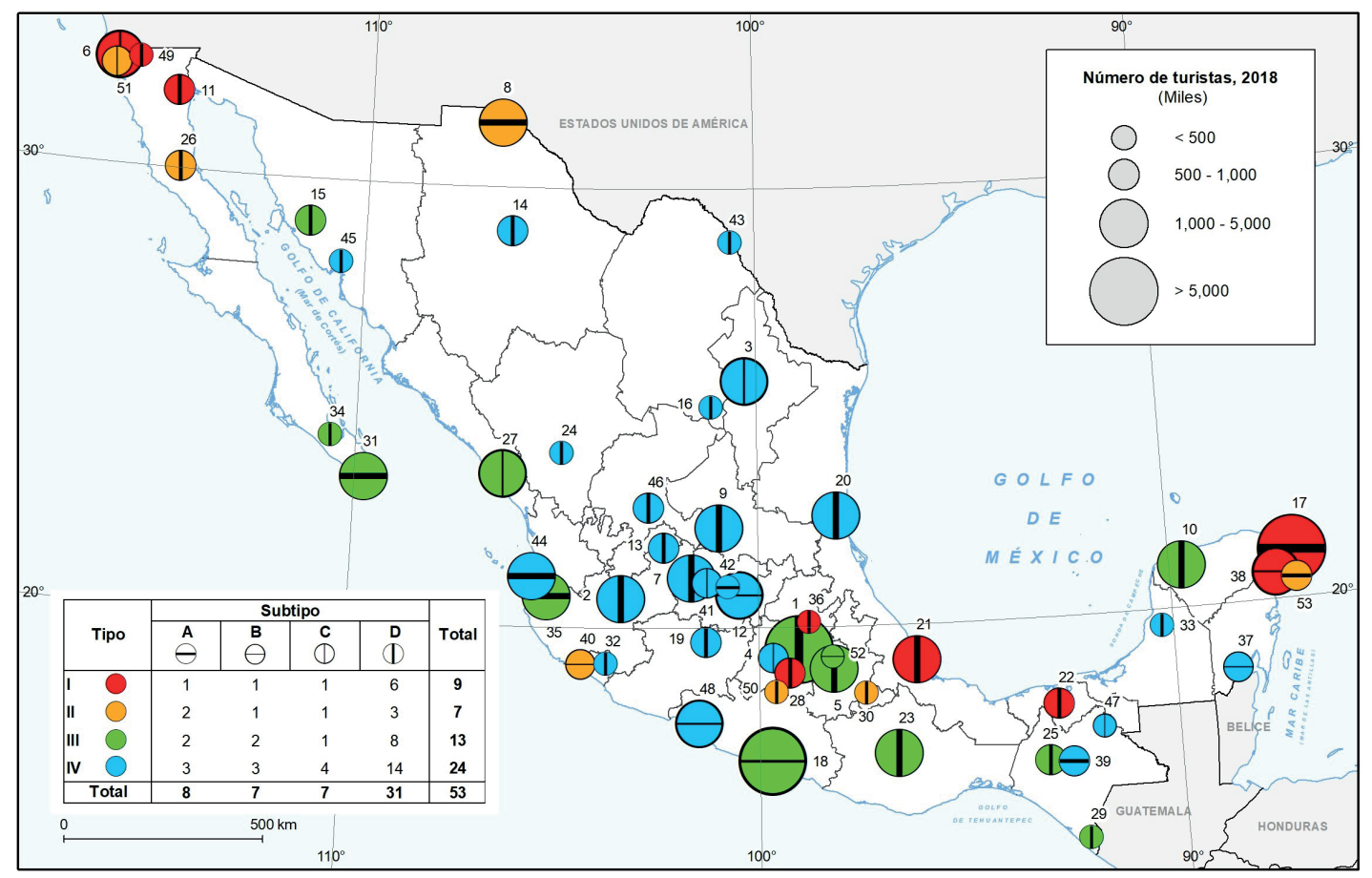

Fuente: Elaboración propia con base en Conapo (2018b); SSA (2020); IMSS (2020); DGE-SSA (2020); Datatur (2018).

La cantidad de territorios turísticos por tipos y subtipos es contrastante: mientras algunos escenarios tipológicos distinguen a conjuntos de cuatro territorios o más (I-D, III-D, IV-D), otros, por el contrario, solo caracterizan un caso; esto es evidencia del carácter singular o repetible de las relaciones cuantitativas entre los indicadores. La tipología revelada se relaciona y comenta a continuación.

Tabla 1. Tipo I: Mayores tasas de contagios y letalidad

\begin{tabular}{l|c|}
\multicolumn{1}{|c|}{ Subtipos } & Territorios turísticos \\
\hline $\begin{array}{l}\text { A. Menor disponibilidad de camas y mayor caída porcentual } \\
\text { del empleo turístico formal }\end{array}$ & Cancún \\
\hline $\begin{array}{l}\text { B. Mayor disponibilidad de camas y mayor caída porcentual } \\
\text { del empleo turístico formal }\end{array}$ & Playa del Carmen \\
\hline $\begin{array}{l}\text { C. Menor disponibilidad de camas y menor caída porcentual } \\
\text { del empleo turístico formal }\end{array}$ & \begin{tabular}{c} 
Tijuana \\
\hline $\begin{array}{l}\text { D. Mayor disponibilidad de camas y menor caída porcentual } \\
\text { del empleo turístico formal }\end{array}$
\end{tabular} \\
\hline
\end{tabular}

Fuente: Elaboración propia con base en figura 5. 
Cancún se presenta como el caso más crítico del conjunto de territorios turísticos seleccionados, tanto por los atributos concernientes al tipo (mayores tasas de contagio y letalidad) como a los del subtipo (menor disponibilidad de camas hospitalarias y mayor descenso porcentual del empleo turístico formal). Este lugar, que emergió como "emblema" de los Centros Integralmente Planeados en los años 70, se distingue como un centro selectivo y preferencial del mercado turístico norteamericano; no es casual que comparta su situación menos favorable con el destino colindante de Playa del Carmen, solo diferenciado, a nivel de subtipo, por su mayor disponibilidad de camas hospitalarias; este escenario se caracteriza por una acentuada movilidad micro-regional de la población local y de turistas en la porción restante de la Riviera Maya, incluido Cozumel.

En contraposición, los subtipos $C$ y $D$, si bien registran una incidencia crítica de COVID-19, tienen mayor disponibilidad de camas hospitalarias y menor caída del empleo turístico, casos de Mexicali, Veracruz, Villahermosa, Cuernavaca, Pachuca y Tecate. Tijuana, por su parte, se separa de este escenario por reportar una menor disponibilidad de camas. Estos territorios turísticos se distinguen por una importante movilidad, interna y externa, de la población residente y no residente, suscitada por la existencia de aeropuertos y un puerto; son los casos de cuatro capitales estatales (Mexicali, Villahermosa, Cuernavaca, Pachuca), de tres ciudades fronterizas (Tijuana, Mexicali, Tecate) y del puerto de Veracruz.

Tabla 2. Tipo II: Mayor tasa de letalidad con menor tasa de contagio

\begin{tabular}{|l|c|}
\hline \multicolumn{1}{|c|}{ Subtipos } & Territorios turísticos \\
\hline $\begin{array}{l}\text { A. Menor disponibilidad de camas y mayor caída } \\
\text { porcentual del empleo turístico formal }\end{array}$ & Ciudad Juárez, Cozumel \\
\hline $\begin{array}{l}\text { B. Mayor disponibilidad de camas y mayor caída } \\
\text { porcentual del empleo turístico formal }\end{array}$ & Manzanillo \\
\hline $\begin{array}{l}\text { C. Menor disponibilidad de camas y menor caída } \\
\text { porcentual del empleo turístico formal }\end{array}$ & Playas de Rosarito \\
\hline $\begin{array}{l}\text { D. Mayor disponibilidad de camas y menor caída } \\
\text { porcentual del empleo turístico formal }\end{array}$ & Ensenada, Tehuacán, Taxco \\
\hline
\end{tabular}

Fuente: Elaboración propia con base en la figura 5.

Estos territorios acaparan la atención, en tanto se alejan del escenario probable (tipo I, aunque el tipo III rompe la relación probabilística); sería significativo saber, por medio de estudios de caso, las condiciones específicas en estos territorios que pudieran explicar el comportamiento contradictorio de la ocurrencia de una alta tasa de letalidad en circunstancias de menor contagio. Los escenarios más críticos 
de este tipo son Ciudad Juárez y Cozumel; la mayor letalidad que los distingue se relaciona, además, con condiciones de menor disponibilidad de camas hospitalarias y una alta afectación en los empleos turísticos.

A pesar de lo señalado inicialmente, estos casos pudieran tener explicaciones causales relacionadas con su singular localización geográfica: Cozumel, insular, está inserta en la importante región turística Cancún-Rivera Maya, con acentuada movilidad poblacional; en tanto, Ciudad Juárez es parte de la trama urbana que conforma con El Paso, Texas, correspondiendo una intensa interacción humana y económica.

En contraparte, el subtipo D, con análogo comportamiento en la tasa de letalidad, se equilibra con una mayor disponibilidad de camas hospitalarias y menores afectaciones en los empleos turísticos: este escenario más favorable se identificó en Ensenada, Tehuacán y Taxco. Por su parte, los subtipos intermedios B y C se asocian con características que refuerzan el carácter crítico del tipo: el primero se distingue por la disminución de los empleos turísticos (Manzanillo), mientras que el segundo registra una menor disponibilidad de camas hospitalarias (Playas de Rosarito); en una primera aproximación, sería admisible pensar que la cercanía de este último a Tijuana pudiera explicar este comportamiento pero no es así; también Tijuana registró valores de disponibilidad de camas hospitalarias por debajo de la media nacional del indicador.

Tabla 3. Tipo III: Menor tasa de letalidad con mayor tasa de contagios

\begin{tabular}{|l|c|}
\hline \multicolumn{1}{|c|}{ Subtipos } & Territorios turísticos \\
\hline $\begin{array}{l}\text { A. Menor disponibilidad de camas y mayor caída } \\
\text { porcentual del empleo turístico formal }\end{array}$ & Los Cabos, Puerto Vallarta \\
\hline $\begin{array}{l}\text { B. Mayor disponibilidad de camas y mayor caída } \\
\text { porcentual del empleo turístico formal }\end{array}$ & Acapulco, Tlaxcala \\
\hline $\begin{array}{l}\text { C. Menor disponibilidad de camas y menor caída } \\
\text { porcentual del empleo turístico formal }\end{array}$ & \multicolumn{1}{|c|}{ Mazatlán } \\
\hline $\begin{array}{l}\text { D. Mayor disponibilidad de camas y menor caída } \\
\text { porcentual del empleo turístico formal }\end{array}$ & $\begin{array}{l}\text { Valle de México, Puebla, Mérida, Hermosillo, } \\
\text { Oaxaca, Tuxtla Gutiérrez, Tapachula, La Paz }\end{array}$ \\
\hline
\end{tabular}

Fuente: Elaboración propia con base en la figura 5.

El tipo III se caracteriza por una alta tasa de contagio que no implica una alta letalidad; es el escenario identificado en Los Cabos y Hermosillo, que reportan tasas de letalidad por debajo del $4 \%$. No obstante, a nivel de los subtipos A, B y C, se detectan tres escenarios problemáticos: menor disponibilidad de camas hospita- 
larias y, al mismo tiempo, una mayor reducción en empleos turísticos (subtipo A: Los Cabos y Puerto Vallarta); una mayor reducción en los empleos turísticos pero en circunstancias de mejor disponibilidad de camas hospitalarias (subtipo B: Acapulco y Tlaxcala); y menos afectación en el empleo turístico en condiciones de menor disponibilidad de camas hospitalarias (subtipo C: Mazatlán). Estos escenarios corresponden con destinos turísticos preferenciales para el turismo interno (Acapulco) y extranjero (Los Cabos y Puerto Vallarta).

El subtipo $D$ describe al mejor contexto entre los que reportan mayor tasa de contagio con menor letalidad, con condiciones de mayor disponibilidad de camas hospitalarias y menores afectaciones en empleo turístico. Junto al Valle de México, Puebla, Hermosillo y La Paz, aparecen dos capitales estatales y una ciudad fronteriza del sursureste: Oaxaca, Tuxtla Gutiérrez y Tapachula. Las medidas de casi nula movilidad y "sana distancia" repercutieron aquí en forma diferencial por causas que merecen ser estudiadas. ¿Por qué el Valle de México, principal aglomeración poblacional, así como puerto de entrada y salida más importante del país, se comportó con baja letalidad mientras otros, esencialmente del tipo I y II, reportaron altas tasas de letalidad, incluso con menor tasa de contagio (tipo II) aunque todos se sometieron a las mismas medidas? Quizá, la mayor presencia de infraestructura hospitalaria (camas) podría explicar, en el caso del Valle de México y resto de capitales estatales, la menor letalidad.

Tabla 4. Tipo IV: Menores tasas de letalidad y contagio

\begin{tabular}{|c|c|}
\hline Subtipos & Territorios turísticos \\
\hline $\begin{array}{l}\text { A. Menor disponibilidad de camas y mayor caída } \\
\text { porcentual del empleo turístico formal }\end{array}$ & San Cristóbal de las Casas, San Miguel de Allende, Nuevo Vallarta \\
\hline $\begin{array}{l}\text { B. Mayor disponibilidad de camas y mayor caída } \\
\text { porcentual del empleo turístico formal }\end{array}$ & Querétaro, Chetumal, Ixtapa-Zihuatanejo \\
\hline $\begin{array}{l}\text { C. Menor disponibilidad de camas y menor caída } \\
\text { porcentual del empleo turístico formal }\end{array}$ & Monterrey, Toluca, Guanajuato, Palenque \\
\hline $\begin{array}{l}\text { D. Mayor disponibilidad de camas y menor caída } \\
\text { porcentual del empleo turístico formal }\end{array}$ & $\begin{array}{c}\text { Guadalajara, León, San Luis Potosí, Aguascalientes, Chihuahua, } \\
\text { Saltillo, Morelia, Tampico, Durango, Colima, Campeche, Piedras } \\
\text { Negras, Guaymas, Zacatecas }\end{array}$ \\
\hline
\end{tabular}

Fuente: Elaboración propia con base en la figura 5.

Este tipo, que concentra casi la mitad de los territorios turísticos examinados, presenta las mejores condiciones relativas relacionadas con la incidencia de COVID-19 (menores tasas de contagio y letalidad); aquí se reúnen ciudades muy pobladas del país, como Guadalajara y Monterrey (el Valle de México es cercano a este escenario, 
aunque tiene tipo III debido a una mayor tasa de contagios). Sin embargo, en el nivel de subtipos, se detectan territorios menos favorecidos (subtipo A), por menor disponibilidad de camas hospitalarias y mayor afectación en los empleos turísticos: San Cristóbal de las Casas, San Miguel de Allende y Nuevo Vallarta que, con diferentes localizaciones geográficas y mercados turísticos distintos, pueden ser calificados como destinos preferenciales del turismo extranjero.

El subtipo $B$, similar al anterior en cuanto a la disminución del empleo formal en el sector turismo, tiene un mejor escenario en disponibilidad de camas hospitalarias: Querétaro, Chetumal e Ixtapa-Zihuatanejo responden a estas condiciones, que combinan la menor incidencia de COVID-19 del conjunto, con afectaciones importantes en el empleo turístico. El subtipo $C$, por su parte, se presenta como el opuesto al escenario anterior: con la menor incidencia relativa de la enfermedad, se distingue por la menor disponibilidad de camas hospitalarias, aunque, en forma favorable, la variación del empleo formal en el turismo no fue tan negativa; aquí se reúnen tres capitales estatales con importante capacidad hotelera y acentuada movilidad poblacional (Monterrey, Toluca y Guanajuato) y Palenque, destino de paso para turistas nacionales y extranjeros.

El perfil tipológico más favorable (menor incidencia de COVID-19, mayor disponibilidad de camas hospitalarias y menor afectación al empleo turístico) se detectó en la mayor cantidad de territorios estudiados (14 casos). Pertenecen a este tipo algunas capitales estatales y ciudades de relevancia económica del norte y occidente del país (Guadalajara, Colima, León, San Luis Potosí, Aguascalientes, Chihuahua, Saltillo, Morelia, Tampico, Durango, Zacatecas, Piedras Negras y Guaymas, conjunto al que se une Campeche). En forma sorprendente, son territorios de acentuada movilidad poblacional, aún transfronteriza en el caso de Piedras Negras, que no implicó la detección de mayores incidencias de COVID-19; en particular, Tampico, Colima, León, Piedras Negras, San Miguel de Allende e Ixtapa-Zihuatanejo tienen una tasa baja de letalidad $(<4 \%)$. 


\section{Conclusiones}

La pandemia de COVID-19, cuyas primeras manifestaciones territoriales a escala mundial corresponden al inicio del año 2020, ha provocado consecuencias negativas en la movilidad de la población, a escala personal (casa, ámbito cotidiano de vida) y planetaria (posibilidad de viajar, de visitar otros países). A inicios de junio de 2020, la Organización de la Naciones Unidas, por medio de su secretario general, Antonio Guterres, manifestó que, ante la aparición de COVID-19, la idea de viajar está en declive, el sentimiento de miedo al alza y que el futuro es incierto. Esto, en términos territoriales, tiene enormes consecuencias en el futuro inmediato y mediato en cuanto a cómo la población ve, vive y concibe el espacio, desde una escala particular de vida hasta la dimensión planetaria y que, por supuesto, comprende la necesidad de viajar, de trasladarse a sitios diferentes del lugar habitual de residencia.

La tipología formada de territorios turísticos según incidencia del COVID-19 revela patrones de comportamiento heterogéneos que refutan la presunción más ordinaria: mientras mayor sea la tasa de contagios, mayor será la de letalidad. Sólo en los casos de territorios agrupados en el tipo I se confirma esta relación fenomenológica. Los tipos II y III corresponden con escenarios distintos: el más crítico, que demuestra lo opuesto (menor tasa de contagio con mayor letalidad: tipo II), y el de mayor tasa de contagio que no implicó una mayor tasa de letalidad (tipo III); el tipo IV, por su parte, demuestra la relación probable en sentido opuesto (menores tasas en ambos indicadores).

En este sentido, los territorios turísticos de México se enfrentarán a un proceso de recuperación y mitigación de consecuencias de la emergencia epidemiológica desde diversos escenarios, desde los más críticos (tipos I y II), hasta los relativamente menos críticos (tipos III y IV que comprenden la mayor parte de los territorios examinados en esta investigación).

Los tipos revelados reportaron subtipos que indican problemas locales y de consecuencias negativas en el empleo turístico: la menor disponibilidad de camas y mayor caída en el empleo turístico (subtipo $D$, que agrupa una significativa cantidad de territorios turísticos del país). Este hecho implica, en el proceso de recuperación pospandemia, un mayor esfuerzo por parte de las autoridades y agentes que intervienen en la actividad turística de estos territorios. Podría afirmarse que los problemas señalados (fragilidad en el empleo turístico y disponibilidad de camas 
hospitalarias) eran condiciones latentes en estos territorios que se manifestaron visiblemente durante la emergencia sanitaria.

En consonancia con los resultados de esta investigación, se puede afirmar que la mayoría de los lugares estudiados no enfrentaron una situación de emergencia derivada del número de casos registrados, muertes o carencia de infraestructura de atención a la salud. Sin embargo, en ese grupo numeroso de territorios no se incluyen aquellos que desempeñan un papel más significativo en la economía del turismo en México, como Cancún o Tijuana que, en la tipología elaborada, corresponden con situaciones más desfavorables.

Desde el principio, estos destinos enfrentaron un escenario de incidencia alta y muy alta, generado después de la disminución sensible en la llegada de turistas y el descenso en las conexiones aéreas. Este estado de cosas prevalecerá por varios meses más hasta que las condiciones sanitarias en todo el mundo sean más confiables. Ante este escenario, los turistas podrán optar, siendo las cosas iguales en todos los destinos, por viajar o visitar sitios cercanos a su lugar de residencia, en los primeros momentos de la reactivación que, por lo demás, será diferenciada territorialmente en todos los países del mundo.

En este sentido, la situación actual es poco alentadora; por un lado, Estados Unidos, importante emisor de turistas hacia México, se ha convertido en el principal foco de la epidemia a nivel mundial, con un nuevo incremento del número de contagios tras la reapertura de la actividad económica, aunque sus cifras positivas, en términos de recuperación de empleos, son un signo alentador que podría conllevar una reactivación del turismo, con cifras inferiores al escenario prepandemia. Los flujos procedentes de Europa (sobre todo de España, Francia e Italia) se verán, probablemente, afectados por una recesión más severa y prolongada, lo que, unido al cierre de sus fronteras con México, generará un menor y más tardío regreso de sus turistas al país. A esto se suman los problemas económicos de tour-operadores y aerolíneas que, también, inciden en forma negativa en la rehabilitación del turismo sobre todo internacional, en el país.

Es previsible que en México el turismo nacional sea el primero en reactivarse ya que, para inicios de julio de 2020, las fronteras con los países vecinos continuaban cerradas, con una consecuencia negativa para la movilidad turística regional (América del Norte, América Central y el Caribe). Al interior, los destinos de playa cercanos a ciudades grandes (Acapulco respecto a la Ciudad de México, y Puerto Vallarta en 
consideración de Guadalajara, destinos que no fueron tan afectados, según la tipología que aquí se ha examinado) se podrían reincorporar más rápido a la actividad turística, por su localización geográfica y accesibilidad a centros primarios de origen de turistas.

Finalmente, ante el escenario de crisis grave que enfrenta el turismo por la difusión de COVID-19, se tiene la oportunidad histórica de orbitar hacia modalidades menos masificadas y sostenibles del sector que, además, serían percibidas como más seguras desde el punto de vista sanitario, con independencia de su accesibilidad o popularidad. De ocurrir esto, se transformaría de lleno el escenario territorial del turismo en México y el mundo.

\section{Referencias}

Acevedo, A., Linares, C. y Cachay, O. (2010). Tipos de conocimiento y preferencias para la resolución de problemas. Revista de la Facultad de Ingeniería Industrial, 13 (2), 25-37. https://doi.org/10.15381/idata.v13i2.6181

Buzai, G. (2020). De Wuhan a Luján. Evolución espacial del COVID 19. Posición, Revista de la Universidad de Luján, 3. https://bit.ly/35uLo57

Consejo Nacional de Ciencia y Tecnología (Conacyt). (2020). Datos actualizados sobre incidencia de COVID-19. https://coronavirus.gob.mx/.

Consejo Nacional de Población (Conapo). (2018a). Delimitación de las zonas metropolitanas de México 2015. Sedatu-Conapo-INEGI. https://bit.ly/3mcyXRo

Consejo Nacional de Población (Conapo). (2018b). Proyecciones de la población de México y de las entidades federativas, 2016-2050. Gobierno de México. https:// bit.ly/2ZycOTP

Datatur. (2018). Compendio estadístico del turismo en México 2018. Secretaría de Turismo. https://bit.ly/3kcMkiF

Dirección General de Epidemiología - Secretaría de Salud (DGE-SSA). (2020). COVID-19. Base de datos del día 4 de junio de 2020. Gobierno de México. https://www.gob. $\mathrm{mx} / \mathrm{salud} /$ documentos/datos-abiertos-152127.

El Universal. (2020, 31 de marzo). Mapa. Así llego el coronavirus a México. https://bit. ly/3meAmqA 
García de León, A. (2020). Indicadores básicos y tendencias espacio-temporales en 20 países por mortalidad COVID-19. Posición, Revista de la Universidad de Luján, 3. https://bit.ly/3hxvYj7

Gasca, J. (2020) Zona metropolitana de Cancún. En Instituto de Geografía (Ed.), Atlas de vulnerabilidad urbana ante COVID-19 en las zonas metropolitanas de México. Instituto de Geografía y Universidad Nacional Autónoma de México. https:// doi.org/10.14350/atlas.13.covid

Granados, R., Villaseñor, A. y Toscana, A. (2020). En Instituto de Geografía (Ed.), Atlas de vulnerabilidad urbana ante COVID-19 en las zonas metropolitanas de México. Instituto de Geografía y Universidad Nacional Autónoma de México. https:// doi.org/10.14350/atlas.13.covid

Instituto Mexicano del Seguro Social (IMSS). (2020). Asegurados. Gobierno de México. http://datos.imss.gob.mx/group/asegurados.

Instituto de Geografía. (Ed.). (2020). Atlas de vulnerabilidad urbana ante COVID-19 en las zonas metropolitanas de México. Instituto de Geografía. Universidad Nacional Autónoma de México.

Johns Hopkins University. (2020). Coronavirus pandemic map. http://coronavirus.jhu. edu

Koch, T. (2017). Cartographies of disease. Maps, mapping and medicine. Redlands, ESRI Press.

Padilla, S., Vargas, E. y De Sicilia, R. (2020). Zona metropolitana de Tijuana. En Instituto de Geografía (Ed.) Atlas de vulnerabilidad urbana ante COVID-19 en las zonas metropolitanas de México. Instituto de Geografía. Universidad Nacional Autónoma de México. https://doi.org/10.14350/atlas.13.covid

Propin, E. (2003). Teorías y métodos en geografía económica. Instituto de Geografía, Universidad Nacional Autónoma de México.

Propin, E. y Sánchez, A. (2007). Tipología de los destinos turísticos preferenciales en México. Cuadernos de Turismo, 19, 149-168. https://bit.ly/35uX1ZH

Propin, E., Sánchez, A. y Alvarado, I. (2017). Niveles de selectividad territorial de los destinos turísticos en México. Cuadernos de Turismo, 39. 495-520. https://doi. org/10.6018/turismo.39.290671 
Salmerón, O. y Hernández, M. (2020). Zona metropolitana de Mérida. En Instituto de Geografía (Ed.) Atlas de vulnerabilidad urbana ante COVID-19 en las zonas metropolitanas de México. Instituto de Geografía, Universidad Nacional Autónoma de México. https://doi.org/10.14350/atlas.13.covid

Santana, G. (2020). Vulnerabilidad diferencial de los Estados mexicanos frente al COVID-19. Posición, Revista de la Universidad de Luján, 3. https://bit.ly/3mgqrRy

Santana, M. (2020). COVID-19 en México: comportamiento espacio temporal y condiciones socioespaciales, febrero y marzo de 2020. Posición, Revista de la Universidad de Luján, 3. https://bit.ly/3mjZyfA

Secretaría de Salud (SSA). (2020). Recursos en salud 2018. http://bitly.ws/9HJa

Suárez Lastra, M., Valdés González, C., Galindo C., Salvador, E., Ruiz-Rivera, N., AlcántaraAyala, I., López-Cervantes, M., Rosales, A., Lee, W., Benítez-Pérez, H., Juárez M., Bringas López, A., Oropeza, O., Peralta, A. y Garnica-Peña, R. (2020). Índice de vulnerabilidad ante el COVID-19 en México. Investigaciones Geográficas, 0. https://doi.org/10.14350/rig.60140

The New York Times. (2020). Coronavirus map: tracking the global outbreak. http:// nytimes.com.

Thürmer, R. (1983). Probabilistische Typisierung Dargestellt am Beispiel der Umlandbedeutung von Zentren in der DDR. Petersmanns Geographieschen Mitteilungen, 2, 89-98.

Villerías, S., Nochebuena, G. y Urióstegui, A. (2020). Análisis espacial de vulnerabilidad y riesgo en salud por COVID-19 en el estado de Guerrero, México. Posición, Revista de la Universidad de Luján, 3. https://bit.ly/2RILEew 